EPISTEME KOINONIA

Revista Electrónica de Ciencias de la Educación, Humanidades, Artes y Bellas Artes

Año III. Vol III. N ${ }^{\circ}$. Enero - Junio, 2020

Hecho el depósito de Ley: FA2018000022 ISSN: 2665-0282

FUNDACIÓN KOINONIA (F.K)

Santa Ana de Coro, Venezuela

Milady Joselyn Molina

http://dx.doi.org/10.35381/e.k.v3i5.532

\title{
Visión descolonizadora de la gerencia transformacional en los circuitos
} educativos

\section{Decolonizing vision of transformational management in educational circuits}

\author{
Milady Joselyn Molina \\ miladyjmolina@hotmail.com \\ Universidad Nacional Experimental Francisco de Miranda, Santa Ana de Coro \\ Venezuela \\ https://orcid.org/0000-0001-7578-5787
}

Recepción: 15 Septiembre 2019

Revisado: 02 Octubre 2019

Aprobación: 15 Octubre 2019

Publicación: 01 Enero 2020

\section{RESUMEN}

La investigación tuvo por propósito principal: Proporcionar una visión descolonizadora de la gerencia transformacional en los circuitos educativos en el contexto del Circuito Educativo $\mathrm{N}^{\circ} 6$ del municipio Colina. La investigación se enmarcó en una metodología fenomenológica y una aproximación historiográfica sobre la visión descolonizadora de la gerencia transformacional en los circuitos educativos, ajustada a los propósitos de la investigación a través de la indagación e interpretación del discurso de los actores involucrados se pretende aproximarse al fenómeno de la gerencia transformacional en su contexto real, Se trabajó con tres gerentes educativos como informantes claves a quienes se les aplicó entrevistas abiertas y análisis fenomenológico de la información. El estilo de la gerencia en el circuito educativo, desde la visión de los informantes clave, se caracteriza por ser justo, legal razonable y respetuoso; además persigue el bienestar colectivo y no individualista.

Palabras clave: Democratización de la educación; política educacional; educación; cultura; antropología de la educación (Palabras tomadas del Tesauro UNESCO). 


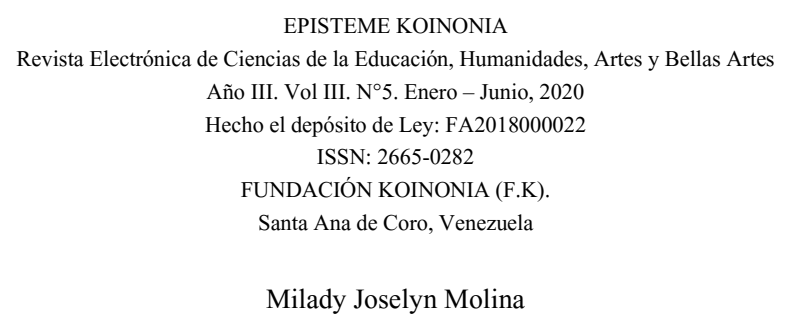

\begin{abstract}
The research had as a main purpose: to provide a decolonizing vision of transformational management in educational circuits context No. 6 of the Colina municipality. The research was framed in a phenomenological methodology and a historiographic approach on the decolonizing vision of transformational management in educational circuits, adjusted to the purposes of the research. Through the investigation and interpretation of the actors' discourse involved, it is intended to approach the phenomenon of transformational management in its real context. Three educational managers were considered as key informants to whom open interviews and phenomenological analysis of the information were applied. The management style in the educational circuit, from the perspective of key informants, is characterized by being fair, reasonable and respectful; It also pursues collective and non-individualistic wellbeing.
\end{abstract}

Keywords: Democratization of education; educational policy; education; culture, educational anthropology. (Words taken from UNESCO Thesaurus).

\title{
INTRODUCCIÓN
}

En los últimos años el proceso educativo en América Latina ha sido centro de reformas y transformaciones con el propósito de alcanzar la calidad en cada uno de su accionar. Por lo tanto, esta transición se inicia desde un paradigma tradicional jerárquico donde la planificación educacional va dirigida a generar el mayor número de ciudadanos que respondan al sector productivo del país. Las sociedades posmodernas demandan cambios y transformaciones educativas, donde la visión educativa este permeada por nuevos paradigmas epistemológicos y por el dinamismo, articulación e integración de todos los colectivos; sin dejar a un lado las diferencias individuales y las características geohistóricas de cada contexto. En este panorama de una sociedad cambiante, se inserta el Estado Docente con nuevas reformas; Bonilla-Molina (2004) indica que:

...el proceso dialéctico como el que actualmente caracteriza a la sociedad nacional, una gran parte de la corriente histórica por el cambio educativo y social de Venezuela [...] decide contribuir al proceso de la revolución democrática Bolivariana, en clara perspectiva de coadyuvar a un proceso transformacional ecológico. (p. 38). 


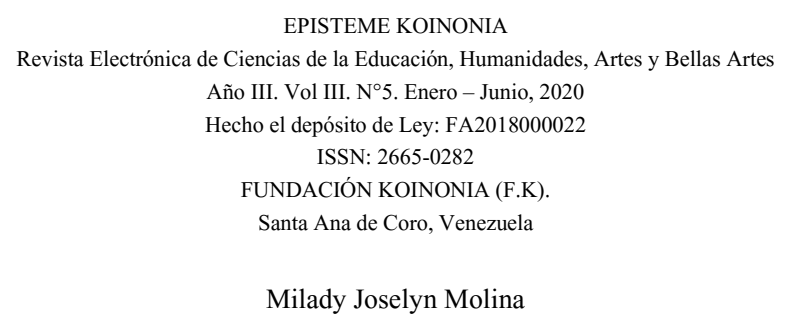

Ante una sociedad dialécticamente cambiante y exigente de cambios en todos los sectores sociales, la educación debe asumir posturas transformacionales ecológicas, entendidas como la visibilización de los saberes ancestrales. En consecuencia, las organizaciones educativas han redimensionado su gerencia para dar respuestas a los retos y demandas de la actual sociedad y ser cada vez más efectivas, eficaces y eficientes, en fin ser un espacio de excelencia y calidad. Asumiendo enfoques epistémicos, paradigmas y teorías transformacionales en lo institucional y pedagógico. En este Sistema-Mundo, la educación venezolana ha reorientado su accionar adecuándose a los procesos de los cambios epocales y transición política, económica y cultural. A través de la transformación institucional y pedagógica; la educación venezolana ha sido partícipe de innumerables y trascendentales cambios en concordancia las demandas de la sociedad posmoderna, que se orienta hacia un nuevo modelo de país republicano y bolivariano, de acuerdo a lo establecido en el artículo $\mathrm{N}^{\circ}$ 102 de la Constitución de la República Bolivariana de Venezuela (1999).

En este sentido, la Constitución de la República Bolivariana de Venezuela establece la democracia participativa y protagónica como sistema de gobierno donde el Estado Docente es el principal garante del proceso educativo, con el propósito de formar un ciudadano que enaltezca sus valores humanos y que participe activamente en la transformación de la sociedad en la que vive. Categorizando la educación como un continuo de desarrollo humano que acciona a través de los procesos de enseñanza, aprendizaje y evaluación.

La educación venezolana actual requiere de cambios profundos, reales y sistemáticos que promuevan la calidad educativa. En este proceso la responsabilidad recae en el personal de las organizaciones educativas; en lo particular, en los directores como gerentes principales. Según Lorenzo \& Ramírez (2016). "la función del director es un factor clave en le mejora de los centros educativos, especialmente en la gestión del cambio" (p. 10).

El director, como gerente, es el responsable principal de gestionar un proceso educativo 


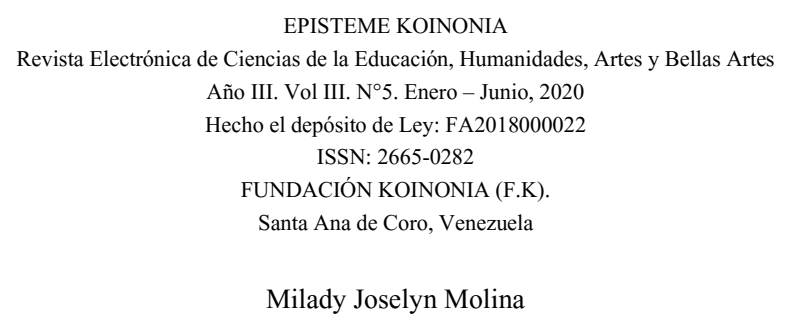

de calidad, eficaz, eficiente y efectivo; para tales objetivos el director debe cumplir con funciones gerenciales; según Chiavenato (1999), son las de "planificación, organización, dirección, control y evaluación, a objeto de utilizar sus recursos humanos, físicos y financieros con la finalidad de alcanzar objetivos, comúnmente relacionados" (p. 146). Todas estas funciones se articulan para lograr el desarrollo integral de las instituciones educativas, así como la transformación de todos los colectivos educativos $y$ de la sociedad en general.

En este sentido, el director debe conocer los diferentes estilos de liderazgos, sus características particulares, categorizar sus aptitudes y actitudes; como lo refiere Navarro (2015) "ser capaz de autoevaluarse, para determinar por sí mismo en cual estilo está ubicado y en consecuencia asumir el estilo que más le convenga, es decir, ser congruente con la realidad contextual" (p. 7).

Evidentemente, resalta la necesidad de generar cambios en el capital intelectual de las organizaciones educativas, permitiendo fortalecer las diferentes capacidades conceptuales, procedimentales, actitudinales, bajo enfoques de paradigmas posmodernos que conciben al líder como un ser transformacional, proactivo, dinámico, creativo, con gran capacidad de influir ante los demás para lograr obtener de manera sinérgica la calidad y productividad en los procesos organizacionales. Esta nueva visión del país exige que las instituciones educativas tengan que reorientar su papel adoptando nuevos modelos e implementando nuevas estrategias educativas orientadas para tales fines.

En el logro de los propósitos educativos la gerencia transformacional es un elemento muy valioso en las organizaciones educativas; desde la visión estratégica organizativa permite no solo las funciones gerenciales básicas, anteriormente señaladas; sino además la comunicación asertiva, toma de decisiones más certeras, así como los enlaces entre las instituciones y la contextualización del proceso educativo.

Evidentemente, en la gerencia educativa actual se hace imprescindible el asumir una nueva visión gerencial que propicie la transformación educativa, desde lo pedagógico e 


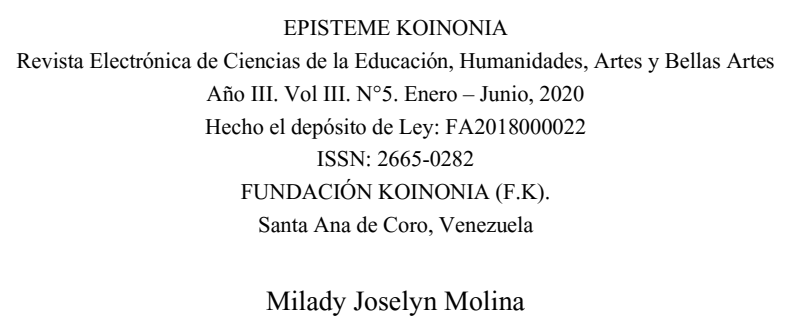

institucional; para lo cual se tiene que adecuar a los nuevos enfoques y paradigmas gerenciales, como es la gerencia transformacional, asumir una gerencia participativa e integradora donde se promueva el trabajo educativo en equipos institucionales.

En otro orden de ideas, no contradictorio, la sociedad venezolana se encuentra en una transición epocal caracterizada en el ámbito educativo por la descolonización epistemológica. A través de este paradigma se establece la necesidad de cambiar la postura epistémica eurocentrista por la visibilización de la cultura originaria, como lo señala Velasco (2015) "el paradigma epistémico que subyace a nuestras praxis sigue siendo en gran medida, la herencia de la invasión, llevada adelante por la espada y la cruz, la corona y la iglesia" (p. 14). Por lo tanto, la descolonización propone la revalorización de las culturas propias de cada comunidad. En el ámbito educativo, esto es la integración de las comunidades a los procesos educativos respetando sus características geohistóricas.

La internalización de la gerencia bajo la visión del paradigma de la descolonización del pensamiento se presenta como un valioso aporte en la gerencia educativa que propicia el fortalecimiento de la idiosincrasia de los colectivos educativos y la transformación de la sociedad al tomar en cuenta las caracterizaciones, las fortalezas, oportunidades y debilidades de cada contexto geohistórico de las organizaciones educativas; así como las cosmovisiones de todos los colectivos educativos y sus individualidades como ser humano y ser social (Alves \& Delmondez, 2015).. Por tanto la gerencia educativa debe ser planteada como un agente de cambio dentro de las sociedades posmodernas y de todos los colectivos educativos.

El gerente educativo debe participar en todos los contextos, tanto educativos como comunitarios, manteniendo una interrelación entre la institución y la comunidad; donde los primeros sean el centro eficaz de planificaciones estratégicas para el desarrollo de la comunidad; y donde los segundos participen corresponsablemente del proceso educativo de las y los estudiantes; a fin de lograr la sociabilidad y la integración de todos los colectivos educativos y comunitarios como un equipo articulado (Zapata, 


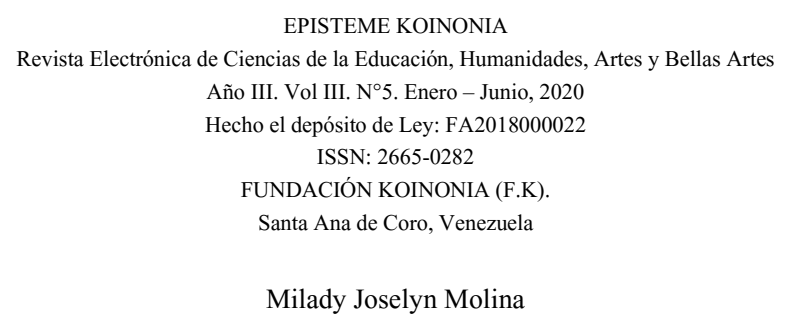

Claudia, 2018). En este sentido, en el gerente educativo venezolano debe prevalecer una visión epistémica descolonizadora y a su vez un pensamiento sistémico que articule la filosofía gerencial transformacional de acuerdo a la sociedad posmoderna y la ejecución estratégica de actividades en un contexto determinado.

El proceso de transformación educativa que se gesta en el país en los últimos lustros requiere de un gerente educativo comprometido con la transformación pedagógica e institucional que reoriente el hecho educativo en concordancia con los propósitos establecidos en la Constitución de la República Bolivariana de Venezuela y la Ley Orgánica de Educación.

Desde esta visión, el Estado Docente se conceptualiza como la integración corresponsable del Gobierno, como garante, y de todos los colectivos sociales y educativos permeada con la participación integral y activa de todos; con el propósito de lograr la formación integral y de calidad de las y los estudiantes de acuerdo a las finalidades educativas. Tomando en cuenta no solo sus individualidades sino además sus realidades geohistóricas y socioculturales.

Articulada al proceso de descolonización epistemológica que se gesta en América Latina, en la educación venezolana se han forjado un conjunto de cambios con la finalidad de lograr la mayor inclusión posible y la calidad educativa; además preservando la integración con las comunidades y la re-valorización de la cultura propia de cada una y sus realidades geohistóricas. Visibilizando, de esta forma los Objetivos Históricos del Plan de Patria 2013-2019 referidos a la educación, tales como, desarrollar programas y actividades en los que incorporen la epistémica ancestral y popular de los pueblos (p. 73); además se prioriza el fortalecimiento de los procesos que permitan visibilizar la identidad histórico-comunitaria a través de la reproducción de su memoria histórica y la promoción de las múltiples manifestaciones y tradiciones de las distintas comunidades. (p. 145).

Durante los últimos lustros las reformas, proyectos y programas educativos han pretendido alcanzar la calidad educativa, en un proceso de "marcha y contramarcha" se 


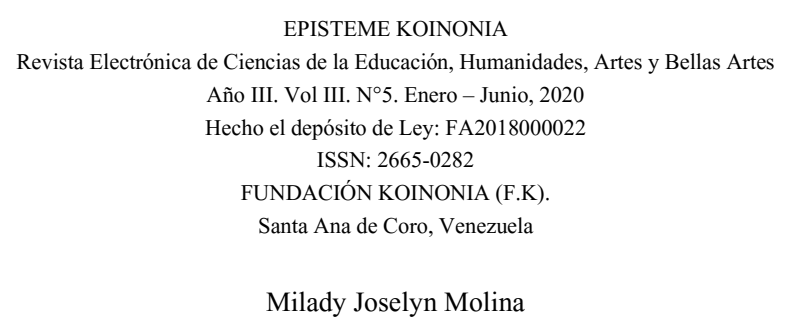

han asumido un conjunto de cambios en los diferentes niveles y modalidades educativas: Escuelas Bolivarianas, CEIS, Simoncitos, Séptimo Bolivariano, "horarios bolivarianos e integrales"; Misiones Educativas (Robinson, Ribas, Sucre); Aldea Universitaria; programas socioeconómicos (PAE, Becas); programas educativos (Colección Bicentenario, Canaima); Diseño Curricular Bolivariano; entre otros. Todos con la finalidad de lograr la mayor inserción y prosecución educativa de niños, niñas, adolescentes y jóvenes. Las estadísticas comprueban que este propósito ha sido alcanzado, se ha logrado la mayor inclusión educativa en el decurso de la historia educativa venezolana.

La evaluación por la calidad educativa, del 2014, arrojó como resultado que ésta en todo el proceso educativo no se encuentra en los niveles planeados y/o deseados. Por consiguiente, el Estado Docente ha asumido esta realidad como una problemática mayor que debe ser superada; para lo cual ha ideado operaciones estratégicas, tales como: Programa Nacional de Formación Avanzada, Transformación Pedagógica en Media General y Transformación Institucional.

Con la primera estrategia se establecen estudios de pos grado para los docentes en ejercicio, a fin de que continúen y actualicen su formación académica. La segunda estrategia plantea el cambio y contextualización pedagógica (áreas de formación, integración de asignaturas), a fin de que los estudiantes adquieran y participen activamente en una formación integral y de calidad. La tercera estrategia se plantea el cambio en la gerencia y administración de la estructura organizacional, a través de la creación de los circuitos educativos.

En esta perspectiva, el Estado Docente asume políticas socioeducativas que permitan la integración de las comunidades a las organizaciones educativas; como son los Circuitos Educativos, con la finalidad de crear acciones estratégicas que favorezcan la integración de las comunidades, preservación de los acervos culturales, valoración de los contextos geohistóricos. Como integrantes todos estos aspectos de un mismo sistema-mundo que se articulan para alcanzar finalmente la calidad educativa. 


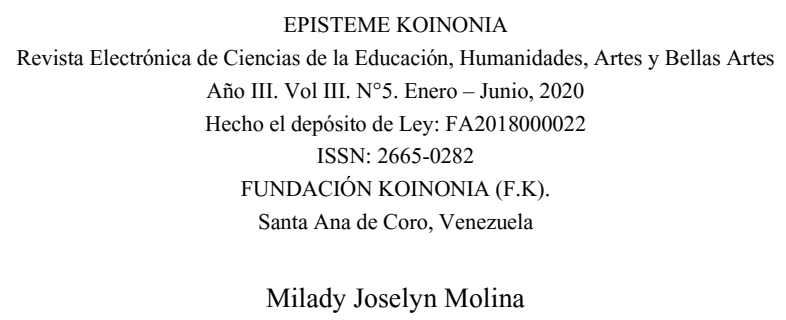

La dialéctica propicia el cuestionamiento sobre sí los circuitos educativos dan respuestas al objeto de su creación; es decir, ¿estos responden al proceso de descolonización epistemológica del pensamiento; acaso responden a enfoques gerenciales emergentes y transformacionales, responden a una efectiva articulación organizacional, a una eficiente comunicación y a una eficaz unión entre las instituciones educativas; a la par de la promoción de las comunidades y su cultura ancestral?

Es así que la investigación tuvo por propósito principal: Proporcionar una visión descolonizadora de la gerencia transformacional en los circuitos educativos en el contexto del Circuito Educativo $\mathrm{N}^{\circ} 6$ del municipio Colina.

\section{MÉTODO}

La investigación se enmarcó en una metodología fenomenológica y una aproximación historiográfica sobre la visión descolonizadora de la gerencia transformacional en los circuitos educativos, ajustada a los propósitos de la investigación a través de la indagación e interpretación del discurso de los actores involucrados se pretende aproximarse al fenómeno de la gerencia transformacional en su contexto real.

Ajustada a la metodología fenomenológica en vista de que el proceso de descolonización del pensamiento en el ámbito educativo así como la conformación de los circuitos educativos no han sido abordados y por lo tanto sus interpretaciones no son fáciles, así lo señala Martínez (1989) al referir que "es el más indicado cuando el investigador no ha vivido ni le es nada fácil formarse ideas y conceptos adecuados sobre el fenómeno que estudia" (p. 5).

Se trabajó con tres gerentes educativos como informantes claves: una supervisora territorial y dos directoras del Circuito Educativo $N^{\circ} 6$, pertenecientes al Consejo de Directoras; quienes han gerenciado en las instituciones respectivas desde antes de la conformación de los Circuitos Educativos, aportando así una perspectiva más confiable sobre los mismos. Con la información que aportaron las informantes claves por medio de entrevistas abiertas, se realizaron las categorizaciones y triangulación. 


\section{RESULTADOS}

\section{Cuadro 1}

Categoría: Descolonización del Pensamiento

$\begin{array}{llll}\text { Subcategoría Informante } & \text { Informante 2 Informante 3 }\end{array}$

1

\begin{tabular}{|c|c|c|c|c|}
\hline & $\begin{array}{l}\text { Es una } \\
\text { estrategia } \\
\text { innovadora, } \\
\text { la } \\
\text { agrupación } \\
\text { de las } \\
\text { instituciones } \\
\text { educativas } \\
\text { con } \\
\text { realidades } \\
\text { muy } \\
\text { similares. } \\
\text { Estamos en } \\
\text { la } \\
\text { expectativa } \\
\text { de lo que } \\
\text { pueda } \\
\text { obtener en } \\
\text { resultados } \\
\text { que } \\
\text { debieran } \\
\text { ser en } \\
\text { común. Más } \\
\text { que positivo }\end{array}$ & 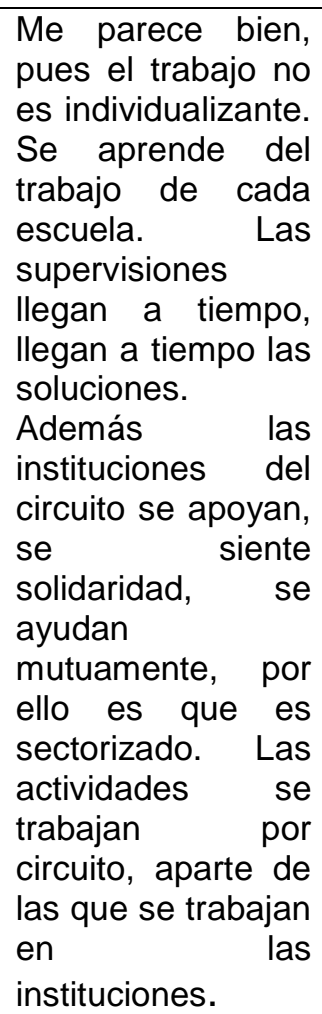 & 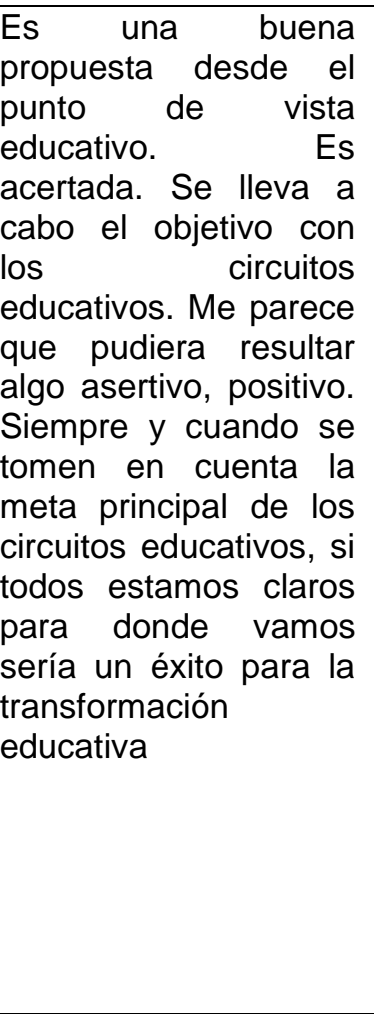 & $\begin{array}{l}\text { De las respuestas de las } \\
\text { informantes claves se } \\
\text { desprende que tienen } \\
\text { pleno conocimiento sobre } \\
\text { el proceso de } \\
\text { transformación } \\
\text { institucional. } \\
\text { Se concibe como una } \\
\text { propuesta innovadora, } \\
\text { asertiva y positiva; que } \\
\text { promueve el trabajo en } \\
\text { equipo, tomando en } \\
\text { cuenta las características } \\
\text { similares de las } \\
\text { comunidades. }\end{array}$ \\
\hline
\end{tabular}

\section{Cuadro 2}

Categoría: Gerencia transformacional

$\begin{array}{lllll}\text { Subcategoría } & \text { Informante } 1 & \text { Informante } 2 & \text { Informante } 3 & \text { Inferencia }\end{array}$

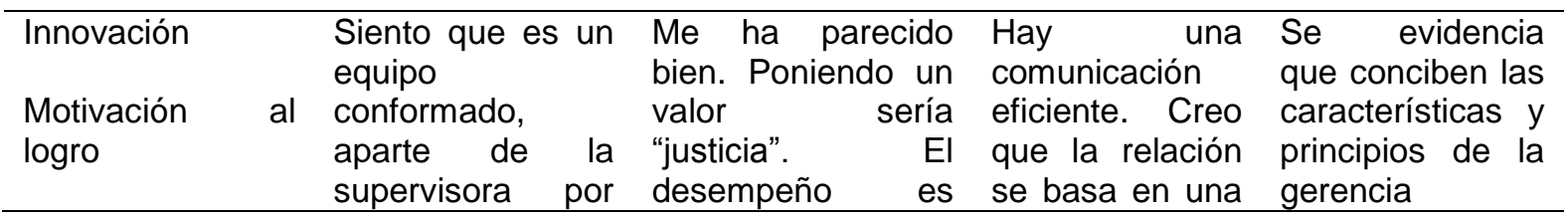


EPISTEME KOINONIA

Revista Electrónica de Ciencias de la Educación, Humanidades, Artes y Bellas Artes

Año III. Vol III. N ${ }^{\circ}$. Enero - Junio, 2020

Hecho el depósito de Ley: FA2018000022 ISSN: $2665-0282$

FUNDACIÓN KOINONIA (F.K).

Santa Ana de Coro, Venezuela

Milady Joselyn Molina

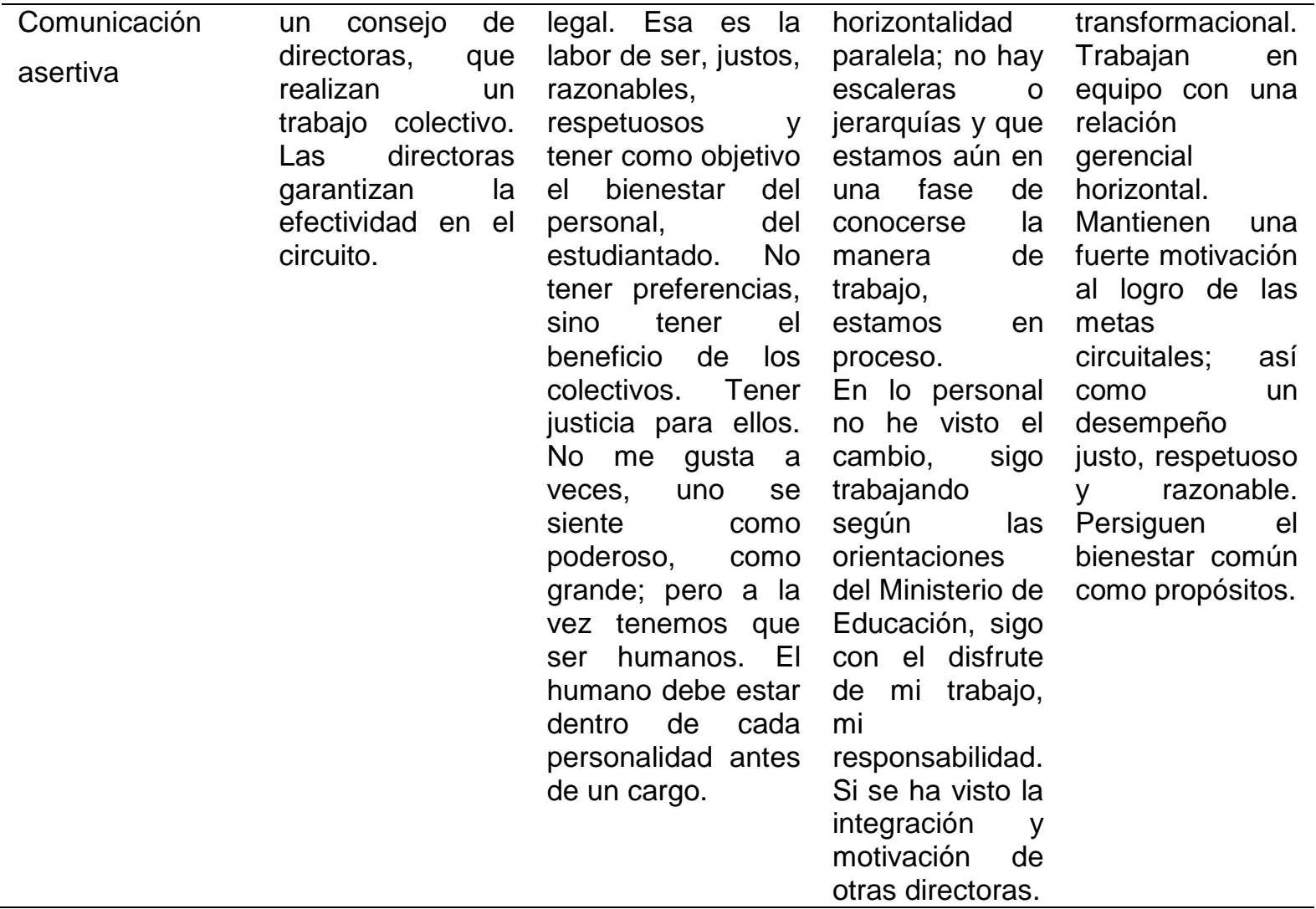

\section{DISCUSIÓN}

La reflexión sobre la investigación, ha propiciado la categorización de la Descolonización Epistemológica en los contextos educativos, la cual permea al actual el proceso de transformación histórica, política y sociocultural en Venezuela, al ser parte de un sistema-mundo, y en América Latina. Visibilizándose como una de las dimensiones de la actual transición epocal del decurso histórico.

La descolonización epistemológica es un proceso histórico determinante que confronta las posturas eurocentrista a través de la revaluación de los saberes ancestrales de los pueblos que han sido invisibilizados y dominados. Otorgándole al "otro" su importancia epistemológica y ontológica (Aldana Zavala, 2019).

En segundo orden, los procesos de reformas y transformación por la calidad educativa 


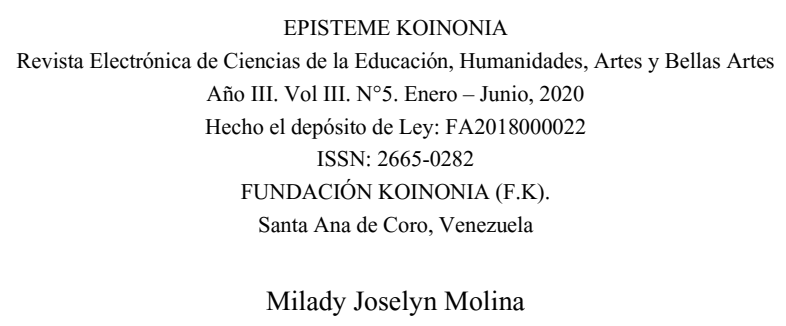

promueven la emersión de estilos gerenciales cónsonos a las realidades epocales del país y a la realidad de las sociedades posmodernas, se presenta así la gerencia transformacional, dejando a un lado los estilos jerárquicos e instaurando una gerencia horizontal con la creación de los circuitos educativos (Guanipa Ramírez, Albites Sanabria, Aldana Zavala \& Colina Ysea, 2019).

Estos tienen como una de sus finalidades la integración de las instituciones educativas y la participación activa de las comunidades. Adquiriendo estas un rol cada vez más activo y protagónico. Desde esta cosmovisión, se toma en cuenta en la planeación educativa los saberes ancestrales de las comunidades así como sus características geográficas, históricas y culturales (Jiménez-Vargas \& Montecinos-Sanhueza, 2019).

En esta perspectiva, en la gerencia transformacional se asumen modelos de liderazgos no jerárquicos que faciliten la integración y participación de todos los colectivos. Destacando elementos como liderazgos transformacionales y emergentes, comunicación asertiva, emprendimiento, motivación al éxito, integración, cultura organizacional, respeto a la biodiversidad geohistórica (Martínez, 1999).

Ciertamente, se evidenció en el estudio la existencia de debilidades gerenciales, propias de un proceso de transformación pedagógica e institucional que recién se está implementando y se encuentra en pleno proceso, al cual los colectivos educativos, actores sociales de las comunidades se han ido integrando de manera activa y adecuando su praxis según los fines educativos.

La nueva visión de país, dentro de la transición política y económica ha sido permeada por el proceso transcendental de descolonización del pensamiento; en la cual se revaloriza el papel de las comunidades y sus contextos geohistóricos así como su cultura ancestral; se toma en cuenta las fortalezas y debilidades de las comunidades para el desarrollo de los procesos educativos. Se respeta los saberes ancestrales así como la historia y de cada comunidad; logrando así la inserción de las comunidades en el devenir histórico-educativo de las mismas. La gerencia transformacional se concibe en la transición epocal como una "gerencia georencial", categoría que debe ser 


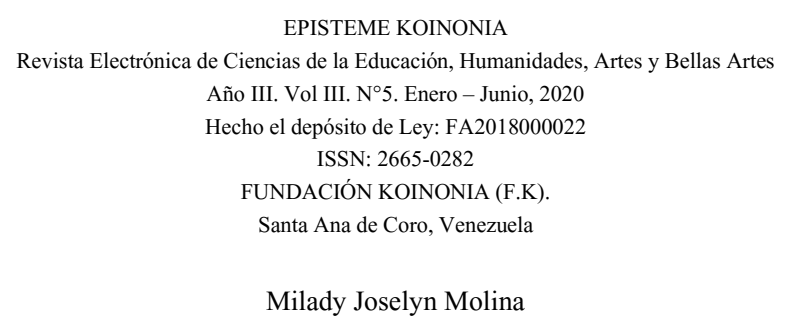

abordada en futuros estudios.

\section{REFLEXIONES DE CIERRE}

Los informantes clave describen lo que se categoriza como fortalezas de la gerencia transformacional en el Circuito Educativo $N^{\circ} 6$, tal es el caso de lograr una eficiente comunicación asertiva, la cual se evidencia en el control y seguimiento de las actividades planeadas, en colectivo, en el circuito. Destacando que las instituciones que conforman este circuito educativo mantienen realidades geohistóricas similares.

Los informantes clave refieren que la conformación de los circuitos educativos es una estrategia innovadora que permite la unión de instituciones educativas cercanas y con realidades geohistóricas similares. Lo cual se encuentra concatenado a los propósitos del proceso de descolonización del pensamiento y la reforma educativa; donde se revaloriza la cultura autóctona ancestral, las condiciones geográficas; además de enfoques gerenciales emergentes. Aun así, al ser proceso que recientemente se está llevando a cabo, hay expectativas de los resultados.

Los informantes clave refieren que el trabajo en el circuito no es individualizante, por el contrario es colectivo y favorece el aprendizaje de todas las instituciones que conforman el circuito educativo. Además al ser sectorizado se toma en cuenta las características geohistóricas de las comunidades y se promueve una gerencia transformadora efectiva; donde las informaciones y el control llegan a tiempo.

El estilo de la gerencia en el circuito educativo, desde la visión de los informantes clave, se caracteriza por ser justo, legal razonable y respetuoso; además persigue el bienestar colectivo y no individualista. En otras palabras promueve la transformación no sólo de los lideres sino también de todos los colectivos; preservando el humanismo en todo momento y acciones.

\section{FINANCIAMIENTO}

No monetario 
EPISTEME KOINONIA

Revista Electrónica de Ciencias de la Educación, Humanidades, Artes y Bellas Artes

Año III. Vol III. N ${ }^{\circ}$. Enero - Junio, 2020

Hecho el depósito de Ley: FA2018000022

ISSN: 2665-0282

FUNDACIÓN KOINONIA (F.K)

Santa Ana de Coro, Venezuela

Milady Joselyn Molina

\section{AGRADECIMIENTOS}

Un especial agradecimiento a mi familia por el apoyo en el desarrollo de esta investigación.

\section{REFERENCIAS}

Aldana Zavala, J. J. (2019). La competencia epistemológica en el investigador social universitario venezolano. [Epistemological competence in the Venezuelan university social researcher]. Praxis, 15(1), 103-115. https://doi.org/10.21676/23897856.3091

Alves, C, \& Delmondez, P. (2015). Contribuições do pensamento decolonial à psicologia política. [Contributions of decolonial thought to political psychology].Revista Psicologia Política, 15(34), 647-661. Recuperado de http://pepsic.bvsalud.org/scielo.php?script=sci arttext\&pid=S1519549X2015000300012\&lng=pt\&tlng $=$.

Bonilla-Molina, L. (2004). Educación en tiempos de revolución bolivariana. [Education in times of the Bolivarian revolution]. Recuperado a partir de https://n9.cl/e8ygf

Constitución de la República Bolivariana de Venezuela (1999). [Constitution of the Bolivarian Republic of Venezuela]. Gaceta Oficial №5453. Caracas: Venezuela. Recuperado a partir de: https://www.oas.org/dil/esp/constitucion_venezuela.pdf

Chiavenato, I. (1999). Introducción a la Teoría General de la Administración. [Introduction to the General Theory of Administration]. (5 Edición). Editorial McGraw-Hill. Bogotá.

Guanipa Ramírez, L., Albites Sanabria, J., Aldana Zavala, J., \& Colina Ysea, F. (2019). Educación para la ciudadanía y la democracia: El equilibrio del poder. [Education for citizenship and democracy: The balance of power]. IUSTITIA SOCIALIS, 4(6), 71-89. http://dx.doi.org/10.35381/racji.v4i6.290

Jiménez-Vargas, F., \& Montecinos-Sanhueza, C. (2019). Polifonía en educación multicultural: enfoques académicos sobre diversidad y escuela. [Polyphony in multicultural education: academic approaches to diversity and school]. Magis, Revista Internacional De Investigación En Educación, 12(24), 105-128. https://doi.org/10.11144/Javeriana.m12-24.peme 


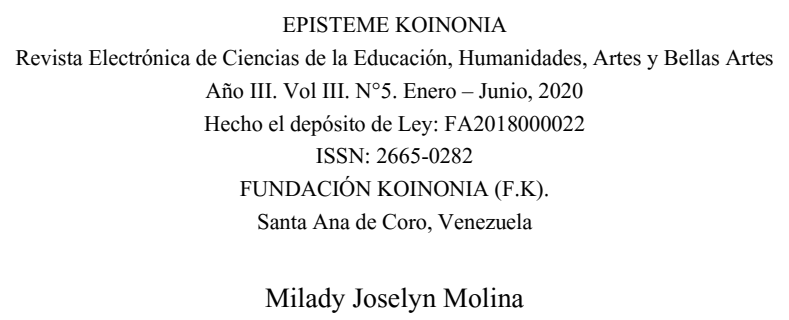

Lorenzo, E., \& Ramírez, A. (2016). Pasado, Presente y Futuro. Procesos y Procedimientos en la Evaluación de los Directores y Directoras de los Centros Escolares de Andalucía. [Past, present and future. Processes and Procedures in the Evaluation of the Directors of the Andalusian School Centers.] Revista Iberoamericana De Evaluación Educativa, 3(2). Recuperado de https://n9.cl/byh2

Martínez, M. (2006). La investigación cualitativa (síntesis conceptual). [Qualitative research (conceptual synthesis)]. Recuperado a partir de https://n9.cl/9oxi

Martínez, M. (1999). La nueva ciencia. Su desafío, lógica y método. [The new science. Its challenge, logic and method] Editorial Trillas S.A. México.

Navarro, A. (2015) Liderazgo transformacional, una alternativa para los Directivos de los centros de Educación de la población de Boca de Pozo municipio Península de Macanao estado Nueva Esparta. [Transformational leadership, an alternative for the Directors of the Education centers of the population of Boca de Pozo, Macanao Peninsula municipality, Nueva Esparta state.] Universidad Pedagógica Experimental Libertador.

Plan de la patria. Segundo Plan Socialista de Desarrollo Económico y Social de la Nación 2.013-2.019. [Homeland plan. Second Socialist Plan for Economic and Social Development of the Nation 2013-2019] Gaceta oficial №6118. Extraordinario 4 diciembre de 2.013. Recuperado a partir de https://n9.cl/mkey

Velasco, R. (2015). Historia de una Resistencia. Sobre el encubrimiento del Pueblo Caquetío y su Exclusión de la Historia. [History of a Resistance. On the cover-up of the Caquetío People and their Exclusion from History]. Recuperado a partir de https://n9.cl/6w9i

Zapata, Claudia. (2018). El giro decolonial. Consideraciones críticas desde América Latina. [The decolonial turn. Critical considerations from Latin America]. Pléyade (Santiago), (21), 49-71. https://dx.doi.org/10.4067/S0719-36962018000100049

(C2020 por el autor. Este artículo es de acceso abierto y distribuido según los términos y condiciones de la licencia Creative Commons Atribución-NoComercial-Compartirlgual 4.0 Internacional (CC BY-NC-SA 4.0)

(https://creativecommons.org/licenses/by-nc-sa/4.0/). 